\title{
"O mundo existia em retalhos": um estudo da problemática da arte na literatura brasileira e portuguesa
}

\author{
Daniele dos Santos Rosa ${ }^{1}$
}

RESUMO: Este artigo tem por intuito investigar a relação contraditória entre o trabalho estranhado e a arte, como paradigma do trabalho livre. Ao relacionar as obras Vidas Secas, de Graciliano Ramos; Avieiros, de Alves Redol; Aparição, de Vergilio Ferreira; e "A enxada" de Bernardo Élis, busca-se compreender as dificuldades e os limites do trabalho do escritor em luta contra a reificação de sua obra.

ABSTRACT: This article intends to investigate the contradictory relationship between estranged labor and art, as a paradigm of free labor. By relating the works Vidas Secas (Barren Lives) by Graciliano Ramos, Avieiros by Alves Redol, Aparição (Apparition) by Vergilio Ferreira and "A Enxada" by Bernardo Élis, it seeks to understand the difficulties and limitations implied in the writing of an author who strives to fight the reification of his work.

PALAVRAS-CHAVE: Arte; Trabalho; Literatura Portuguesa

KEYWORDS: Art; Labor; Portuguese Literature

A Literatura, como produção cultural da humanidade, assume, em nações periféricas como Brasil e Portugal, uma importância fundamental: é a expressão máxima de valor de um povo ao mesmo tempo em que precisa transfigurar as contradições desse mesmo povo. Como expressão de valor serviu como ferramenta de formação nacional, no Brasil, ao participar de nosso projeto civilizatório e de desenvolvimento, ou, em Portugal, como possibilidade de compreensão da decadência histórica, em que seus heróis são poetas, como Camões e Pessoa.

Brasil e Portugal têm histórias diferentes de formação, no entanto seus destinos se cruzam ao serem ambos responsáveis como agentes

\footnotetext{
${ }^{1}$ Doutoranda em Literatura da Universidade de Brasília. Título da pesquisa: "Qué es lo que hay aqui?": um estudo sobre as contradições entre a fantasmagoria e a realidade no discurso literário da obra de Juan Rulfo. Contato: danysr@gmail.com
} 
históricos do processo modernizador que deu um novo rumo à história humana: Portugal com suas navegações e a abertura para um mundo globalizado; e o Brasil, ainda como "terra de ninguém", é parte importante para a concretização do novo modo de produção e da formação de novas forças produtivas.

É a partir dessa relação que o nascente capitalismo se formula por meio da permanência de formas produtivas pré-capitalistas e dá às relações sociais um caráter ao mesmo tempo novo e velho: essas relações se pautam por meio de trocas comerciais, permitidas pela liberdade da livre iniciativa, ao mesmo tempo em que sua produção estrutural, ou seja, o trabalho que estrutura essa própria ação, fundamenta-se na não-liberdade. Essa contradição inerente e necessária para a produção e reprodução da ordem capitalista se coloca de forma disfarçada, encenada, pois :

O paradoxo crucial dessa relação entre a efetividade social da troca da mercadoria e a "consciência" dela é que - para usar novamente uma formulação concisa de Sohn-Rethel - "esse não-conhecimento da realidade é parte de sua própria essência": a efetividade social do processo de troca é um tipo de realidade que só é possivel sob a condição de que os indivíduos que dela participam não estejam cientes de sua lógica própria; ou seja, é um tipo de realidade cuja própria consistência ontológica implica um certo não-conhecimento de seus participantes - se viéssemos a "saber demais", a desvendar o verdadeiro funcionamento da realidade social, essa realidade se dissolveria. (ZIZEC, 1999, p. 43)

Essa contradição, ou paradoxo inicial para Zizec, constitui-se como uma das bases das relações capitalistas e tem na divisão social do trabalho um de seus aspectos fundamentais, pois "as relações fundamentais de toda a sociedade humana são, portanto, as relações de produção [...] os relacionamentos de produção, isto é, os relacionamentos fundamentais dos homens com a natureza e dos homens uns com os outros durante o trabalho" (LEFREVRE, 2009, p. 65). Nesse sentido, formula-se um importante problema para a critica literária, e fundamental a este artigo: como a arte se coloca ou se posiciona nesta contradição? Sabe-se que a arte assume um papel relevante, pois como trabalho humano está inserida nessas contradições. No entanto, como está estruturado esse caráter diferenciado? 
Esse questionamento inicial parte de alguns problemas comuns tratados em quatro importantes obras literárias, de quatro autores diferentes, mas que se aproximam pela escolha e seleção temática e, principalmente, pelas questões que suas obras buscam problematizar. Essas obras são: Vidas secas, de Graciliano Ramos; Avieiros, de Alves Redol; Aparição, de Vergílio Ferreira; e no conto "A enxada”, de Bernardo Élis. As publicações seguem a ordem descrita, compreendendo o período de 1930 a 1970, período este importante para a história da humanidade, que compreende a Segunda Guerra Mundial, o embate entre capitalismo e socialismo, os governos ditatoriais e as transformações do capitalismo por meio de crises e de fortalecimento do sistema financeiro.

Essas obras se aproximam não só temporalmente, mas por tratarem de uma problemática comum: as contradições do trabalho e a exploração do homem. Assim, em Vidas Secas e em Avieiros, temos a exploração da pobreza de famílias, que sem possibilidade de posse alguma, sofrem as consequências de uma pobreza extrema; em Aparição e em "A enxada", temos dois personagens, Bailote e Supriano, que excluídos do mundo do trabalho, estão impossibilitados de sobreviver: o primeiro enforca-se; o segundo acaba por morrer ao destruir seu próprio corpo na tentativa de plantar arroz.

Nesse sentido, essas obras, guardadas suas características peculiares, tratam de um problema social e histórico: a divisão do trabalho, em que este deixa de ser, para alguns, forma de explorar a criatividade humana para tornar-se processo de exploração, chegando-se ao seu extremo: a morte do individuo. No entanto, a questão do trabalho, da divisão entre trabalho estranhado e não-estranhado, se apresenta na arte para além de sua temática, pois a obra literária é também trabalho e faz parte dessa divisão, já que como trabalho intelectual diferencia-se do trabalho braçal, mas precisa tratar em si de seu contrário, ou melhor, parece necessitar carregar-se da contradição dessa divisão.

Nesse sentido, como esses autores, inseridos em momentos peculiares da história humana, em nações em que a permanência do trabalho précapitalista foi essencial para a realização capitalista na sua abrangência como sistema-mundo, trataram dessa questão? Que dilema e como se coloca na 
obra o problema do trabalho artístico e do trabalho alienado? Como suas obras, ao tratarem da exploração do trabalho, puderam equacionar esse dilema?

Essas questões, fundamentais na crítica literária, formulam-se porque a arte literária, como parte do mundo e ao mesmo tempo um mundo à parte, assume na sociedade moderna uma problemática inerente. É a partir de sua autonomização, de sua separação da vida, que a arte tenta se estabelecer além da mesquinhez. No entanto, é caro o preço que paga: está sempre no embate para não se reificar ao mesmo tempo em que contribui para a produção do mundo reificado.

Assim, a problemática da arte está em sua gênese como arte moderna, como parte fundamental na divisão do trabalho. Este se tornou no mundo modernizado, capitalista, estranho ao homem; "os produtos do trabalho do homem escapam à sua vontade, à sua consciência, ao seu controle" (LEFREVRE, p. 42), pois ao assumirem formas abstratas escravizam e oprimem os homens, "tornam-se abusivamente, um concreto ilusório e, todavia, demasiado real, que oprime o concreto verdadeiro: o humano" (LEFREVRE, p. 43).

Diante disso, é preciso entender de que forma a arte, em especial a produção artística periférica, como possibilidade de criação desse mundo à parte, enfrenta os dilemas que se colocam por meio das relações sociais estabelecidas por essa divisão no mundo do trabalho. Esse trabalho é estranho ao homem porque a capacidade de produção é vendida como força de trabalho, alienando o trabalhador de sua capacidade criativa de produção, colocando-se em oposição ao trabalho da arte, como tentativa de romper com as amarras e, por meio de uma ação criativa, impedir a alienação e, ainda, possibilitar a compreensão das estruturas que produzem e reproduzem a alienação.

É nesse sentido que o trabalho artístico, contrapondo-se ao mundo a que pertence, assume uma posição importante: como parte do trabalho humano, ou seja, regido pelas mesmas leis de produção e divisão do trabalho, busca em si se contrapor. No entanto, essa busca da arte, que se liga a sua autonomização na modernidade, carrega em si contradições, já que 
como parte desse mundo precisa, por meio do trabalho estético, tornar-se forma de reconhecimento de si e do mundo.

Essa problemática entre o trabalho artístico e o trabalho estranhado assume em nações periféricas, como Brasil e Portugal, uma força ainda maior. Essa força, contraditória em si, é resultado do papel que a arte assumiu na formação dessas nações, pois como resultado da apropriação de modelos estéticos da grande literatura e como resultado de uma mudança social profunda, precisou conviver com estruturas arcaicas e avessas ao próprio desenvolvimento intelectual. Assim, a arte como parte desse problema da divisão do trabalho ainda se mostra oscilante na complexa relação entre o local e o universal, entre o dominante e o dominado, entre o arcaico e o moderno nas nações periféricas.

Esses embates da própria arte tomaram força em especial nos movimentos modernistas do século $\mathrm{XX}$, como respostas à degradação do homem por meio da intensa destruição promovida pelas grandes guerras mundiais. Essa problemática assumiu nos movimentos do Romance de 1930, no Brasil, e no Neo-realismo, em Portugal, grande força. Cada um desses movimentos, intimamente ligados à situação histórica de seus países, buscava por meio da arte, por meio do ato criativo como trabalho mediado, uma possibilidade de formulação e reconhecimento das contradições inerentes às relações sociais como resultado do sistema econômico vigente.

As obras, aqui destacadas como matrizes dessa problemática, carregam em si esse dilema. Seus autores, inseridos em momentos peculiares de produção artística, precisam e desejam responder às questões desse embate entre a forma literária, produzida em nação periférica, e o processo social, constituído em suas contradições.

Diante dessa necessidade, essa arte literária se propunha como parte do trabalho humano, mas em luta pela desalienação, buscando equacionar tanto quanto possivel as contradições históricas. Assim, essa relação contraditória entre o trabalho estanhado e a arte, como paradigma do trabalho livre, torna-se tema e fundamentação estrutural da obra literária, em que além de por na pauta a exploração do trabalho, ainda encena na sua 
própria estrutura as dificuldades e os limites do trabalho do escritor em luta contra a reificação de sua obra.

É esse o processo encontrado em obras de destaque do Romance de 1930 e do Neorrealismo. Tais obras formulam-se em momentos em que a relação entre literatura e sociedade parece mais nitida. O Romance de 1930, no Brasil, conforme define Bastos (2006), se dá a partir da própria consciência da dificil superação do passado colonial e em consequência da situação de atraso e de periferia à qual o Brasil parecia estar destinado, em que a peculiaridade do local é mais do que uma força estimulante, pois instiga à reflexão do autor enquanto literato e enquanto ser socialmente ativo e privilegiado no próprio contexto social do país, em que se faz necessária não só a produção de uma literatura para o gozo ou o deleite, mas principalmente um campo de ação, cujo projeto literário se constitui como arena possivel para análises, críticas e sugestões, ou seja, como a possibilidade de o autor, em sua condição social, enfrentar as dificuldades da nação.

De forma similar, o Neorrealismo português se processa por meio da eclosão de um movimento associado à resistência antifascista ao final da década de 1930, em que buscava defender uma literatura engajada, voltada para os problemas concretos do país. Assim, a literatura deveria contribuir para a conscientização de questões político-sociais por parte do público leitor e para caracterizar os problemas da estrutura política, econômica e social da sociedade portuguesa.

A maioria dos autores se propunha e se colocava na condição de responsáveis pelo processo de mudança das politicas nacionais, como portavozes da população presa às condições precárias de sobrevivência, em ambientes agrários ou nos bolsões de pobreza que se formavam nas cidades, que não tinha condição possivel de participar ativamente das tentativas revolucionárias desse periodo. No entanto, o empenho desses escritores se defrontava com as peculiaridades do objeto artístico, e o valor estético tornase, além de uma busca do artista, um problema a ser enfrentado, já que se punha a questão: como tratar de realidades tão cruéis por meio da mais elevada arte? 
Essa questão basilar da arte moderna parece fundamentar e se repetir constantemente nas obras propostas para estudo. Pensando inicialmente em Graciliano Ramos e em Alves Redol, autores participantes nos movimentos políticos e de contestação de seus países, vemos que o resultado formal de suas obras, Vidas secas e Avieiros, carrega muito mais que uma estrutura panfletária. Há, nesses romances, uma tentativa de, ao explorar os problemas sociais, ter também presente a necessidade de refletir sobre os problemas da representação, da arte moderna de nações periféricas.

Assim, a saga da família de Fabiano e de Olinda, em que suas formas são determinadas por uma circularidade sem fim, possibilitam uma aproximação a um problema central dessas sociedades - a exploração do trabalho e a negação dos direitos básicos de vida - mas indica também um problema que se estabelece na própria representação desses indivíduos na arte, ou seja, quais ferramentas e quais os limites que os autores precisam enfrentar para que suas obras alcancem, por meio do trabalho estético, esse outro distante socialmente e tenda a uma história totalizadora, que possa captar a história em seu movimento peculiar.

Em Vidas secas, esse processo da representação é trabalhado por meio da negociação entre o personagem iletrado, Fabiano, e o narrador letrado. Como recurso de aproximação, mas também de intensificação das diferenças, o discurso utilizado é o indireto livre, em que há uma certa confusão entre as falas, que podem ora pertencer ao personagem, ora ao narrador. Esse recurso, fundamental em Vidas secas, repete-se também em Avieiros.

Assim, torna-se importante, nessas literaturas pertencentes a momentos de intensificação politica e ideológica, a relação que se estabelece entre o narrador, que a partir da terceira pessoa pode assumir funções amplas na narrativa (aproximando-se muito do autor, como um autor implícito), e os personagens, em sua maioria distantes da vida intelectual. É preciso, então, compreender que nestas obras esta relação entre narrador e personagem se estabelece como forma de poder; ou seja, demonstram em si as relações de poder entre o letrado e o iletrado ou semiletrado, provenientes dessas regiões periféricas. 
Por isso, será essa relação entre narrador letrado e personagem iletrado que aproximará tanto a obra de Graciliano Ramos e de Alves Redol, já mencionadas, como o romance Aparição, de Vergílio Ferreira, e o conto "A enxada", de Bernardo Élis.

Alberto, narrador de Aparição, decide narrar suas experiências de vida e de morte, enquanto professor do liceu, em Évora, em razão da morte de seu pai, e de outras pessoas queridas como Cristina, que morreu aos sete anos e era admirada por seu dom para a música. Ainda no início da sua narração há um acontecimento que mudará ou dará um novo significado aos questionamentos da existência humana realizados pelo jovem professor. Alberto, acompanha Dr. Moura, que vai a uma cidade para tratar de alguns doentes. No entanto, no meio do caminho há um homem, Bailote, conhecido do Doutor, que resolve contar novamente sua triste história. O problema de Bailote é que após uma vida dedicada ao plantio, ao trabalho com a terra, seu patrão lhe diz que seus serviços não são mais necessários, pois suas mãos deixaram de ser boas cultivadoras.

Bailote se vê no centro de um drama: questiona-se como é possivel que suas mãos, sempre grandes e côncavas, mãos de semeador, agora não servem mais. Essa situação é terrivel. O Doutor, já cansado de ouvi-lo, diz que continue a fazer exercícios nas mãos. No entanto, sabe-se que a situação que levou ao descarte dos trabalhos de Bailote foi a modernização do campo. Após a visita do médico a um paciente, ao retornarem, Alberto e o Dr. Moura se espantam com o alvoroço que se forma ali próximo. O médico resolve ver o que aconteceu e, ao retornar transtornado ao carro, espera distanciarem-se muito antes de contar a Alberto que Bailote enforcou-se.

Essa cena, de grande força, assume no romance uma posição dialética: ao mesmo tempo em que é um fato secundário, pois o centro do romance são os questionamentos sobre a existência humana do narrador; torna-se também um elemento primordial, pois todas as questões formuladas por Alberto sobre a vida e a morte terão como base esse acontecimento, o qual se repete constantemente no livro, ou seja, retorna de forma circular na memória do narrador e conduz sua própria narrativa. 
Em "A enxada", temos uma situação muito semelhante. No conto, a vida de Supriano é central à narrativa. Vemos, desde o início, sua saga em busca de uma ferramenta simples e comum no meio rural, mas que está o tempo todo ausente, não é fornecida ao personagem. Impossibilitado, pela falta da ferramenta, de plantar o arroz, frustra-se a determinação de Supriano de pagar com seu trabalho uma dívida que o tornou escravo de um fazendeiro. Isso leva-o a um outro tipo de suicídio: em um momento de loucura, desespero e alucinação, resolve fazer a plantação utilizando suas mãos e apenas um pedaço de madeira. O contato de suas mãos com a terra dura, com as pedras, leva ao esfacelamento de suas carnes, seus nervos e ossos. Essa imagem, vista em partes por sua esposa Olaia, em que a terra era regada a sangue, é finalizada por policiais que o matam, também aterrorizados com a cena, com a transformação de Supriano em ferramenta de trabalho.

Temos, então, nessas duas narrativas, resguardadas suas diferenças, duas cenas muito semelhantes, iguais no horror narrado, mas pertencentes a realidades temporais diferentes e que parecem remeter a um problema mais amplo, mais geral, que rompe as fronteiras nacionais: a exploração do homem.

Há, portanto, uma continuidade temática que se dá entre essas quatro obras, entre as sagas de Fabiano e Olinda, inseridos em uma realidade cruel; e os destinos comuns de Supriano e de Bailote, em que a necessidade de sobrevivência se transforma numa dependência cruel da estrutura exploradora em que não há, como se dá nos romances de Graciliano Ramos e de Alves Redol, nenhum horizonte de mudança, de luta. O que se manifesta é a entrega inevitável do personagem aos modos de exploração: Supriano precisa plantar o arroz; precisa servir e pagar sua divida; Bailote precisa plantar; sua mão ainda pode semear; ou seja, esses personagens parecem pedir, clamar para serem explorados. Afinal, o que isso significa?

Se pensarmos no momento de feitura das obras, Vidas secas e Avieiros pertencem a momentos de perspectiva de mudança: no Brasil havia uma possibilidade de revolução ou ao menos a tentativa de formação dessas forças; em Portugal, fim da década de 1940 e início da década de 1950, há já formulações mais concretas de oposição à ditadura salazarista e a necessidade de formação de posições contrárias. Assim, é possivel relacionar, não 
diretamente, a obra de Graciliano e de Redol, ou seja, a possibilidade de Fabiano tornar-se cangaceiro ou matar o soldado amarelo; ou de Olinda formar uma cooperativa, como reflexão sobre a realidade histórica de suas nações. Como a História, essas obras parecem carregar em si uma esperança de mudança.

No entanto, tais perspectivas de esperança já estão anuladas em "A enxada" e em Aparição. Supriano não vê alternativa: não pode fugir, não pode roubar, não há ninguém que possa ajudá-lo; Bailote está também isolado. Mesmo no Brasil, em que a década de 1950 e 1960 foi marcada pelos embates da Liga Camponesa, isso não se processa nas obras. Na verdade, isso já se processa nas obras anteriores, pois apesar das tentativas de Olinda, a cooperativa não dá certo e os lucros continuam a pertencer ao Tubarão; Fabiano não se torna cangaceiro, nem mata o soldado amarelo e, como reprodução dos destinos dos retirantes, vai com a família para sul, torna-se mais um excluído na cidade, como Macabéa, de $A$ hora da estrela, de Clarice Lispector.

Há, nessas quatro obras, um movimento formal, estrutural, muito característico: a circularidade. Em Vidas secas, as narrativas em capitulos independentes parecem resultar num movimento concêntrico que tem como centro um problema natural, a seca, mas diz respeito muito mais a um problema humano, de estrutura social, que não se encerra nem na forma do romance, nem na vida. Em Avieiros, o movimento é muito semelhante. A diferença está somente no centro: agora o problema natural não é a seca, mas o inverso: as cheias do rio, que destroem todo o ano as moradias dos avieiros e os impede de trabalhar. Assim, tanto para Fabiano como para Olinda, não há um fim para a história: Fabiano reinicia sua caminhada, agora para o sul; Olinda volta a recolher tábuas para seu barraco.

Essa circularidade, que parece se relacionar diretamente à própria estrutura social do capital, que se formula por meio de ciclos, de repetições, da reprodução de sua relação social, parece, de alguma forma, romper-se nas obras posteriores, em Aparição e em "A enxada”. A dependência e a exploração permanecem em sua forma circular, repete-se com Bailote, com Supriano e todos os dois, como semeadores, terão esse destino repetido sempre. No 
entanto, há algo que rompe com essa circularidade. Essa algo é a destruição total do personagem: a morte; o suicídio. Assim, esse rompimento, na verdade, se mostra em seu avesso, um processo cruel de continuidade: é o próprio trabalhador, transformado em ferramenta de produção, que irá reproduzir a estrutura do sistema e ser consumido por ela.

Nesse sentido, esse recrudescimento significa a destruição dos personagens. Que sentido há nessas obras? O que elas têm a dizer, como recurso formal, dessa realidade que elas propõem representar? Que alcance há nessas estruturas que se demonstram circulares e parecem presas a um determinismo sem fim? A partir da distância temporal e da peculiaridade históricas em que estão inseridas, o que suas diferenças e suas permanências têm a nos dizer?

Assim, partindo então de uma temática comum, a exploração do homem no mundo do trabalho, essas obras parecem indicar que além do tratamento desse importante tema, a arte literária também precisa se questionar, refletir sobre suas possibilidades de representação, sobre o seu próprio trabalho. Por isso, ciente da distância que a literatura se colocou do mundo para tornar-se autônoma e crítica, e como isso se problematizou em momentos de profundas contestações politicas e sociais, como nas décadas de 1930 a 1970 no Brasil e em Portugal, é importante perceber como a arte pode tornar-se, como bem salienta Bastos (2009), um consolo, um substituto, um sintoma ou uma recusa.

Cada um desses aspectos diz respeito ao trabalho formal do autor e ao alcance possivel das obras. Por isso, é preciso nos perguntar quais desses pontos predominam nas obras e, a partir desse reconhecimento, alcançar a literatura como processo de anagnorisis ${ }^{2}$ e de antitese da sociedade moderna, capitalista, possibilitando a compreensão de que um mundo outro é possivel, o da liberdade, ativada, então, no efêmero da obra.

É preciso salientar que a seleção de obras a serem estudadas a partir da problemática da arte foi feita sob aspectos ao mesmo tempo aleatórios e

\footnotetext{
2 Ou Anagnórise. É um termo grego, aristotélico, que, como parte da tragédia clássica, consiste no reconhecimento de fatos ou acontecimentos até então insuspeitados, os quais conduzem os personagens a um sentido inesperado e catastrófico. Trata-se, portanto, de uma forma de (re)conhecer, de levar ao conhecimento.
} 
previstos. A aleatoriedade se constitui pela não-rigorosidade na seleção formal, ou seja, para se pensar a problemática da arte em nações periféricas; a forma textual importou no momento em que a temática e algumas estruturas se aproximassem. Assim, sob esse aspecto, o estudo conjunto de um conto e de romances não é invalidado pelas diferenças nas formas peculiares, mas se intensifica por, mesmo por meio de formas diferentes, carregarem uma temática comum e estruturas narrativas muito próximas, como o tipo do narrador e a relação estabelecida entre narrador letrado e personagem iletrado.

A previsibilidade, muito mais fácil de ser percebida, segue outros fatores. As obras se aproximam temporalmente. Tem-se, portanto, uma pequena diferença de anos entre as publicações (de 1934 - Vidas secas, 1945 - Avieiros, 1956 - Aparição e 1966, "A enxada"). Historicamente, no Brasil e em Portugal, esses períodos são marcados por embates políticos e ideológicos entre o socialismo e o capitalismo; há a formação no campo literário de autores engajados em lutas sociais. Há uma nítida influência do Romance de 30 no Neorrealismo, em que autores como Graciliano Ramos, Raquel de Queirós e Jorge Amado são profundamente lidos e tomados como modelos de expressão da luta contra a ditadura salazarista. Isso aproxima nitidamente a obra de Graciliano Ramos a de Alves Redol.

Se pensarmos na obra de Vergílio Ferreira, em que há uma mudança de perspectiva interna, demonstrada no romance Mudança, de 1949, que registra, na verdade, uma mudança mais profunda, no próprio movimento neorrealista e nas necessidades de exploração dos problemas da estética portuguesa, forma-se então, em relação à obra de Alves Redol, um movimento importante, que é ao mesmo tempo de rompimento e de continuidade, que se ligará intimamente com as relações entre a obra literária e o processo social.

Esse movimento, de ruptura e continuidade, que se formula nos sistemas literários como necessidades e respostas aos problemas da representação, também se estabelece entre Vidas secas e "A enxada". Há, portanto, a continuidade temática, a perspectiva regionalista e a formulação de uma consciência dilacerada da realidade nacional, elementos que precisam ser considerados. 
Por fim, a formulação estética de cenas muito parecidas, como a de Bailote e a de Supriano, que em sua força carregam não só os problemas da exploração do trabalho, mas também as impossibilidades e os limites de sua representação. Além disso, conduzem à necessidade de compreensão profunda das mudanças e das permanências que formulam e dão corpo à reprodução do sistema capitalista em nações periféricas e precisam ser entendidas no que representam diante da destruição de seus personagens.

Assim, esse movimento que se estabelece entre a produção da arte como problema na literatura brasileira e portuguesa pode levar a uma compreensão mais totalizadora do mundo e da estrutura do capital, transfiguradas na arte, pois como "a obra literária moderna se desdobra necessariamente numa reflexão sobre seu próprio trabalho" (BASTOS, p. 7), em que estão em jogo, em sua própria forma, os limites do trabalho artístico como contraposição e parte do trabalho humano reificado, em que a obra, ao refletir sobre sua própria construção, quer interpretar essa realidade disfarçada, levar à anagnorisis, ou seja, como conhecimento, conduzir a passagem do ignorar ao conhecer.

Essa passagem de reconhecimento demonstra-se nas obras desse período como ação necessária, que precisa ser empreendida pelo personagem na narrativa, pelo narrador, mas também como necessidade do autor e do leitor, ou seja, como necessidade de povos aos quais foram negadas as próprias possibilidades de compreensão de si e que, na literatura, em sua contradição como mecanismo privilegiado e para poucos, assume grande força, como possibilidade de provocação, de acinte, em que mesmo "amaldiçoado porque lembra ao homem, pelo revés, sua falta de liberdade, mas também [por ser] um espaço da memória (ou nostalgia) da liberdade" (BASTOS, p. 9), de um tempo utópico de plenitude do homem. Torna-se, portanto, uma necessidade da crítica literária que se quer, enfrentando suas limitações, contribuir para o conhecimento do destino humano. 


\section{Referências bibliográficas}

ABDALA JR., Benjamin. A escrita neo-realista. São Paulo: Ática, 1981.

BASTOS, Hermenegildo. "Literatura como trabalho e apropriação" In Remate de males, n. 28.2, Campinas: Unicamp, 2009.

BERGAMO, Edvaldo. Ficção e confissão. Jorge Amado e o Neo-realismo literário português. São Paulo: Unesp, 2008.

CANDIDO, A. Educação pela noite e outros ensaios. 3. ed. São Paulo: Ática, 2000.

DACANAL, J. H. O romance de 30. Porto Alegre: Mercado Aberto, 1982.

ÉLIS, Bernardo. "A enxada" In: Veranico de Janeiro. Rio de Janeiro: J. Olympio, 1966.

FERREIRA, Vergilio. Aparição. São Paulo: Bertrand, 1959.

LEFREBVRE, Henri. Marxismo. Tradução de William Lagos. Porto Alegre: L\&PM, 2009.

NITRINI, S. Literatura Comparada. São Paulo: Edusp, 1997.

RAMOS, Graciliano. Vidas secas. Rio de Janeiro: Record, 1989.

REDOL, Alves. Avieiros. Lisboa: Europa-América, 1972. 